\title{
Persistent gastrointestinal bleeding successfully treated with aminocaproic acid
}

\author{
D. R. GRAHAM \\ M.B., M.R.C.P. \\ R. J. WALKER \\ B.Sc., M.B., F.R.C.P. \\ Department of Gastroenterology, Walton Hospital, Liverpool L9 IAE
}

\begin{abstract}
Summary
An elderly female presented with persistent upper gastrointestinal bleeding from a mucosal lesion in the second part of the duodenum. This failed to respond to surgery, but was successfully treated with aminocaproic acid.
\end{abstract}

\section{Introduction}

Gastrointestinal bleeding from an unknown or inaccessible site in a patient who may not be fit for surgery presents a difficult and not uncommon problem. The following case illustrates an effective and simple form of therapy.

\section{Case report}

A previously well 79-year-old woman presented with a short history of breathlessness. She had been on no drug therapy apart from iron tablets. She drank no alcohol, ate an adequate diet and denied dyspepsia and melaena. Examination showed her to be pale. She had a regular pulse of $90 / \mathrm{min}$ and a blood pressure of $150 / 90 \mathrm{mmHg}$. A systolic murmur was audible over the whole precordium, the jugular veins were elevated to the jaw, there was no peripheral oedema, but she had bilateral basal crepitations. The provisional diagnosis was cardiac failure secondary to anaemia. Investigation showed her haemoglobin was $5.8 \mathrm{~g} / \mathrm{dl}$, white cell count $11 \cdot 1 \times 10^{9} /$ litre, the film showed a normochromic normocytic picture. Blood urea, electrolytes and glucose were normal. Over the next $12 \mathrm{hr}$ she became worse and her haemoglobin fell to $4.7 \mathrm{~g} / \mathrm{dl}$. She was treated with diuretics and transfused. After five units of blood her congestive cardiac failure was improving. Following transfusion her haemoglobin began to fall again and she then passed a melaena stool. Gastroscopy was performed which showed a friable atrophic mucosa, no fresh blood in the stomach, though blood was seen coming from the second part

Correspondence: Dr D. R. Graham, Cardiothoracic Centre, Broadgreen Hospital, Thomas Drive, Liverpool L9 IAE. of the duodenum. Further investigation became available and showed the serum B12 and folate to be normal. Clotting screen was normal and bone marrow showed active haemopoiesis. Barium meal was normal.

She had by then been in hospital for two weeks and had been transfused several times, but her haemoglobin continued to fall. Repeat gastroscopy showed similar findings. She had been treated empirically with cimetidine and later tripotassium dicitrato bismuthate (De-Nol). Because of continued bleeding from the gut mesenteric angiography was thought justified despite her age. This showed a steady ooze from the second part of the duodenum and an angiomatous malformation was not seen (Figs. 1, 2). Deterioration continued and furthe transfusion was required. A laparotomy was per formed on the 40th hospital day which showed mild duodenitis and gastritis. The duodenum was opened and a hypertrophic fold of mucosa below the ampulla of Vater was bleeding and was oversewn. Two feet of jejunum were dissected out and thought to be normal. The gall bladder was also normal.

Postoperatively she made a good recovery and was initially quite well, but on the fourth postoperative day she passed a large melaena stool and her haemoglobin again fell. She was given 2 units of fresh frozen plasma and started on aminocaproic acid $3 \mathrm{~g}$ six hourly. Her haemoglobin was restored to $14 \mathrm{~g} / \mathrm{dl}$ after transfusion. Once started on this antifibrinolytic therapy her haemoglobin was maintained within normal limits and remains so some two months afterward. It is interesting to see how her haemoglobin fell with time when plotted on a graph (Fig. 3). It can be seen that she bled at a steady rate of approximately $1 \mathrm{~g}$ in $24 \mathrm{hr}$. She required 44 units of blood in all over a one-month period. This loss continued postoperatively and was only arrested when she started on aminocaproic acid.

\section{Discussion}

Aminocaproic acid, a potent antifibrinolytic agent, exerts its effect by the inhibition of plasminogen and 


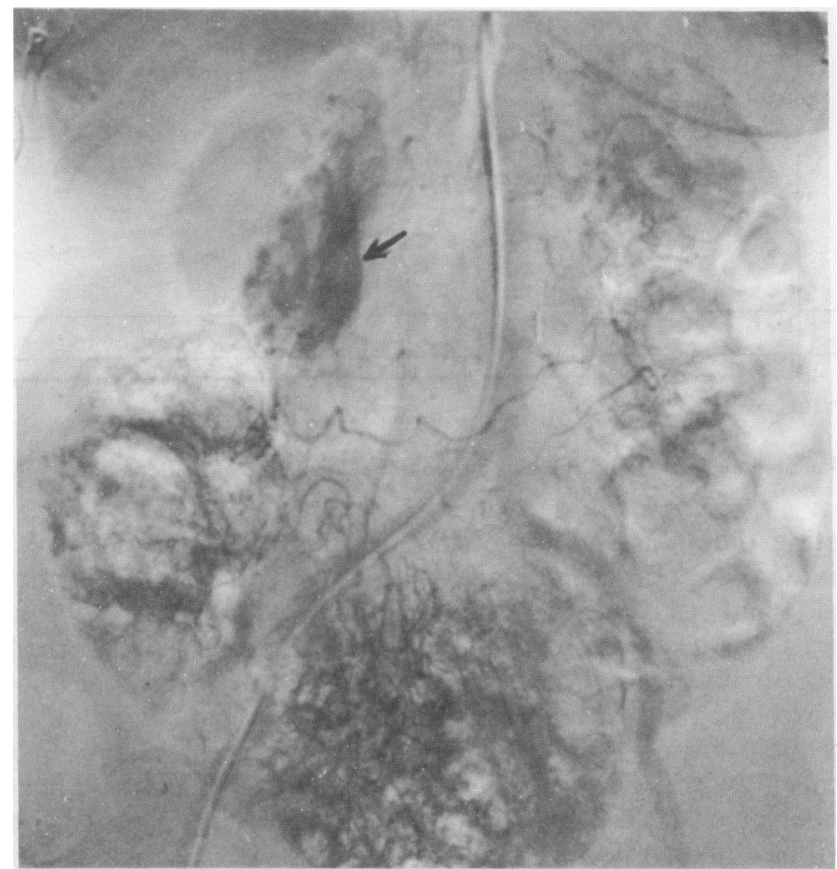

FIG. 1. Early arterial phase superior mesenteric angiogram showing pancreatico-duodenal arcade and filling of the right hepatic artery via this arcade. Suspicious area arrowed.

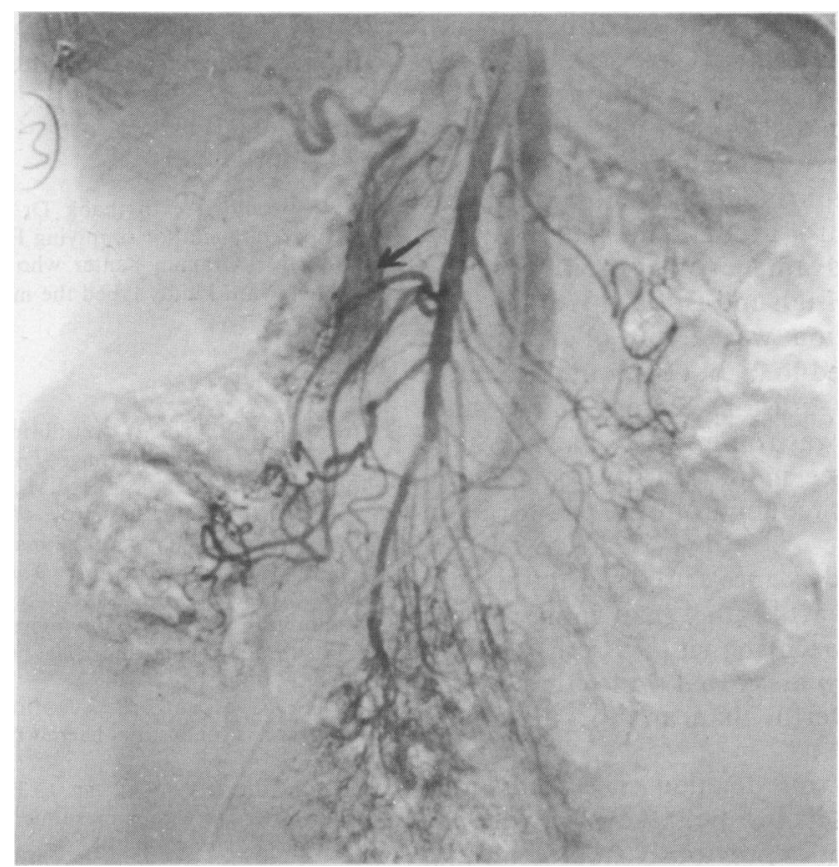

FIG. 2. Late arterial phase superior mesenteric angiogram, showing increased opacification of second part duodenum due to bleeding into duodenal lumen. 


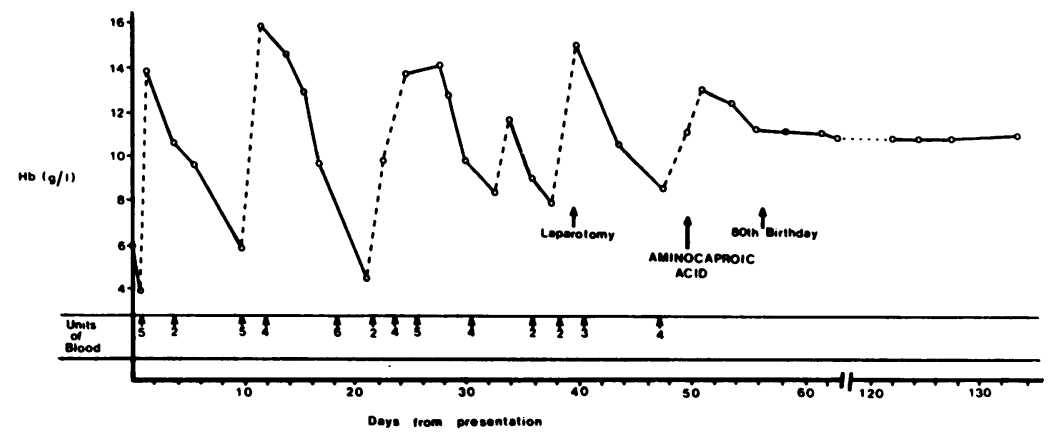

Fig. 3. Haemoglobin levels and transfusion requirements before and after starting aminocaproic acid.

plasmin, thus inactivating the natural action of the fibrinolytic system, leaving the action of the coagulation system unopposed (Prentice, 1979). It is known that there is an increased concentration of tissue plasminogen activator occurring at certain sites; these include the uterus, the prostate and the cerebrospinal fluid following subarachnoid haemorrhage. The role of anti-fibrinolytic agents in bleeding from these sites is well established (Anderson, 1972; Callender, Warner and Cope, 1970; Gibbs and Corhill, 1971; Sack et al., 1972). Regarding the gastrointestinal tract, Cox, Poller and Thompson (1967a) demonstrated increased plasminogen activator and plasmin in the gastric mucosa and gastric vein. They later showed in patients with peptic ulceration increased euglobulin clot lysis time in peripheral blood after handling of the stomach at laparotomy (Cox et al., 1967b). Cormack et al. (1973) in a double blind trial on 150 patients demonstrated that with a negative barium meal the transfusion requirement was less in a group treated with the antifibrinolytic agent, tranexamic acid, than in the control group. The study did not, however, have the advantage of gastroscopy. In a larger trial by Biggs, Hugh and Dodd (1976) the need for surgical intervention was 7 out of 103 in the treated group compared to 23 out of 97 in the control group. A study by Bergquist, Dahlgren and Hessman (1980) on massive gastrointestinal haemorrhage showed little difference in the transfusion requirements and only slight reduction in the death rate in the treated group.

In general these studies above used the antifibrinolytic agent tranexamic acid rather than aminocaproic acid. Recently it has been shown (Nilsson, 1979) by both in vivo and in vitro assay that tranexamic acid is 7-10 times more powerful than aminocaproic acid (Andersson et al., 1968).

The experience of this detailed case study in a single patient would seem to be in keeping with the findings of the large series previously studied, in that antifibrinolytic agents may have a place in the management of a minority of patients with upper gastrointestinal bleeding. The bleeding was controlled after starting aminocaproic acid, but was not affected by surgery. The nature of the bleeding site in the above case is not really known, though it would appear to be from the duodenal mucosa. It is unlikely that the patient would have survived a duodenal resection which is probably the only definitive form of surgery that would have stopped the bleeding. The number of patients with endoscopic negative gastrointestinal bleeding who continue to bleed in a lifethreatening fashion is fortunately small. Our experience with the one patient would suggest that antifibrinolytic agents should be given a trial, particularly in those unfit for surgery. Further study of the plasmin and coagulation systems should be made in these patients as the problem may be there rather than primarily in the mucosa.

\section{Acknowledgments}

We would like to thank Dr David Harty for performing the angiography and for supplying Figs. 1 and 2 . We would also like to thank Mr Graham Santer who performed the laparotomy. Miss Muriel Ward kindly typed the manuscript.

\section{References}

ANDERSON, L. (1972) Antifibrinolytic drugs in the treatment of urinary tract haemorrhage. Progress in Surgery, 10, 88.

Andersson, L., Nilsson, I.M., Collen, S., Granstand, B. \& MELANDER, B. (1968) Role of urokinase and tissue activator in sustained bleeding and the management thereof with EACA and AMCA. Annals of the New York Academy of Sciences, 146, 642.

Bergouist, D., Dahlgren, S. \& Hessman, Y. (1980) Local inhibition of the fibrinolytic system in patients with massive upper gastrointestinal haemorrhage. Upsala Journal of Medical Sciences, 85, 173.

BigGS, J.C., Hugh, T.B. \& DodD, A.T. (1976) Tranexamic acid and upper gastrointestinal haemorrhage-a double blind trial. Gut, 17, 729.

Callender, S.T., Warner, G.T. \& Cope, E. (1970) Treatment of menorrhagia with tranexamic acid-a double blind trial. British Medical Journal, 4, 214.

Cormack, F., Chakrabarti, R.R., Joumah, A.J. \& Fearnley, G.T. (1973) Tranexamic acid in upper gastrointestinal haemorrhage. Lancet, i, 1207. 
Cox, H.T., Poller, L. \& Thompson, J.M. (1967a) Gastric fibrinolysis and possible aetiological link with peptic ulcer. Lancet, i, 1300.

Cox, H.T., Poller, L. \& Thompson, J.M. (1967b) Emdene for the release of gastric fibrinolytic activity into peripheral blood. Gut, $10,404$.

GiBBS, J.R. \& CORHILL, A.G.L. (1971) Use of auto-fibrinolytic agent (tranexamic acid) in the management of ruptured intra-cranial anuerysms. Postgraduate Medical Journal, 47, 19.
NiLSSON, I. (1979) Clinical pharmacology of aminocaproic and tranexamic acids. In: Fibrinolysis and its inhibition. (Ed by Davidson, J.F.) Journal of Clinical Pathology, 33, (suppl. 14), 41. PRENTICE, C.R.M. (1979) Basis of antifibrinolytic therapy. In: Fibrinolysis and its inhibition (Ed by Davidson, J.F.) Journal of Clinical Pathology, 33, (suppl. 14), 35.

Sack, E., Spaet, T.H., Gentile, R.L. \& Hudson, P.B. (1962) Reduction of post prostatectomy bleeding by aminocaproic acid. New England Journal of Medicine, 226, 541. 